\title{
Otimizando a capacidade de crescimento numa cadeia produtiva supermercadista
}

\author{
Luís Henrique Romani de Campos, M.Ec. \\ Doutorando do PIMES/UFPE. \\ E-mail:Ihrcampos@uol.com.br \\ Alexandre Stamford, Dr. \\ Professor Adjunto do Departamento de Economia da UFPE. \\ E-mail: alexandre@stamford.pro.br \\ Maria de Fátima Sales de Souza Campos, M.Ec. \\ Professora Assistente do Departamento de Economia da UEL e Doutoranda do PIMES/UFPE. \\ E-mail:mfcampos@uel.bremfscampos@uol.com.br
}

\begin{abstract}
Resumo
Neste trabalho, investigam-se as vantagens econômicas (e as ações necessárias para obtê-las) que surgem para as cadeias de suprimentos que adotam o Efficient Consumer Response [ECR]. As diretrizes são obtidas a partir das condições de otimalidade de um modelo dinâmico. O instrumental é utilizado para modelar uma cadeia de suprimentos que adote o ECR. Com isto busca-se determinar os impactos da adoção do ECR sobre a adequação da gestão financeira das empresas e as conseqüências sobre a estrutura do setor supermercadista. Evidenciamse também as inter-relações entre os diversos aspectos que devem ser levados em conta na implantação de uma parceria de suprimentos.
\end{abstract}

Palavras-chave

Otimização dinâmica, Cadeia produtiva, Supermercados.

\section{Optimizing growth capacity in a supermarket productive chain}

\begin{abstract}
This paper investigates the economic advantages, which appear to the supply chains that adopt the Efficient Consumer Response (ECR), and also the actions needed to obtain those advantages. The guidelines are found in a dynamic model and its optimality conditions. The instrumental is used to model a supply chain that adopts the ECR. The purpose is to determine the impacts on the financial management and on the structure of the retail market that arise with the ECR adoption. It's shown up the inter-relations among the several aspects that must be considered in the implementation of a supply partnership.
\end{abstract}

Key words

Efficient consumer response, Supply chain management, Supermarkets. 


\section{INTRODUĈ̣̃O}

Nos últimos cinco anos, o setor de supermercados vem passando por um profundo processo de reestruturação produtiva. O ponto de partida desta transformação foi a implantação do Plano Real e a conseqüente estabilização de preços aliada ao fim da correção monetária, que tornaram a estratégia de manutenção de elevados estoques e ganhos financeiros ineficaz para gerar bons resultados aos hiper e supermercados (SANTOS et al., 1998; SANTOS, 1999).

A estabilização provocou ainda um acirramento da concorrência, visto que as distorções de preços passaram a ser notadas, impactando negativamente nas vendas. A queda da correção monetária impulsionou as compras a prazo, principalmente através do cartão de crédito, e proporcionou uma distribuição mais uniforme da demanda, uma vez que os consumidores passaram a fracionar suas compras, tornando-as menos concentradas em um único dia do mês.

Além destas mudanças no cenário macroeconômico, observa-se também no final da década de 90 a entrada de novos grupos internacionais, que passaram a integrar o setor supermercadista brasileiro, levando a uma intensificação das fusões e aquisições no setor.

Essa conjunção de fatores motivou algumas das empresas do setor a implantarem um novo paradigma produtivo, onde a principal técnica administrativa utilizada vem sendo o Efficient Consumer Response (ECR). (SANTOS et al., 1998.)

Neste artigo investigam-se, de forma preliminar, as vantagens econômicas e as ações necessárias para se obter estas vantagens que surgem para as cadeias de suprimentos que adotam o ECR e as diretrizes são obtidas a partir das condições de otimalidade de um modelo de programação dinâmica. $\mathrm{O}$ instrumental será utilizado para modelar uma cadeia de suprimentos que adote o ECR. Com isso, busca-se determinar os impactos da adoção do ECR sobre a adequação da gestão financeira das empresas. Procurar-se-á, também, evidenciar as inter-relações entre alguns aspectos que devem ser levados em conta na implantação de uma parceria de suprimentos.

O artigo apresenta, além desta introdução, uma breve revisão da literatura sobre o supply chain management (SCM) e o ECR, com o intuito de identificar as variáveis relevantes para análise. Em seguida, apresenta-se o modelo proposto, comentando as hipóteses, os resultados obtidos e as limitações da técnica. Finalmente, reúnem-se as principais conclusões.

\section{SUPPLY CHAIN MANAGEMENT [SCM] E EFFICIENT CONSUMER RESPONSE (ECR)}

A principal característica do SCM é a formação de parcerias logísticas entre fornecedor e cliente ao longo da cadeia produtiva. Em versões mais avançadas da técnica, como o ECR, estas parcerias ocorrem inclusive entre concorrentes.

Apesar de ser uma tendência do pós-fordismo a cooperação entre fornecedor e cliente, o SCM e o ECR carecem, para surtirem os efeitos esperados, que os parceiros disponibilizem para a cadeia produtiva informações antes consideradas estratégicas pelas empresas (GARCIA \& CAMPOS, 1999). Níveis de estoque e demanda imediata são duas das

\section{objetivo das empresas é maximizar a capacidade de crescimento (CC).}

mais sensíveis informações que devem ser compartilhadas pelos componentes da cadeia. Esta é uma das principais barreiras a serem vencidas para a implementação do SCM e do ECR. Autores como Mason-Jones \& Towill (1999) chegam a afirmar: "A maior restrição para realizar uma cadeia de suprimentos com dados de venda de mercado é a atitude comum, que considera que informação é poder" (p. 68). ${ }^{\mathrm{i}}$

O Efficient Consumer Response (ECR) é um método de gestão, baseado em um conjunto de técnicas administrativas, que vem sendo adotado nos últimos anos pelo comércio varejista, especialmente pelos hiper e supermercados. Originado do Supply Chain Management, o ECR pode ser considerado um aprofundamento deste. Isto ocorre pois no SCM uma empresa líder utiliza-se de alianças com fornecedores e clientes com o intuito de reduzir o custo logístico total do processo, enquanto o ECR visa, em síntese, reduzir o tempo de resposta às necessidades do consumidor a partir da adoção de parcerias logísticas entre empresas (WOOD \& ZUFFO, 1998).

O ECR é adotado em cadeias de suprimentos com o objetivo de reduzir custos e inventários, aumentar a rapidez no atendimento do consumidor final e propiciar o desenvolvimento de novos produtos com maior aceitação da clientela. A associação do SCM com ECR traz inúmeras vantagens: aumenta a freqüência dos pedidos e das entregas e a eficiência da movimentação logística; uniformiza os lotes; diminui os lead times e reduz a incerteza, pois o EDI permite o conhecimento da demanda por toda a cadeia. Estes efeitos traduzem-se na redução do nível de estocagem e de custos logísticos e, conseqüentemente, na redução da necessidade de capital de giro, proporcionando um aumento no lucro (Figura 1). 
As técnicas adotadas pelo ECR são: custeio baseado em atividades $(\mathrm{ABC})$; quick response; electronic data interchange (EDI) e gerenciamento de categorias ${ }^{i i}$. O ABC permite a detecção das atividades que não agregam valor ao processo, enquanto o EDI permite a disponibilização de informações sobre a demanda final e dos níveis de estoque ao longo da cadeia. O quick response é a adoção do suprimento no menor tempo possível, enquanto o gerenciamento de categorias refere-se à utilização da segmentação de mercado dentro do supermercado.

Para tentar comprovar as vantagens que o SCM traz aos participantes da cadeia de suprimentos, principalmente na redução dos estoques, têm-se efetuado estudos de modelagem matemática. Um destes estudos está descrito no artigo de Figueiredo \& Zambom (1998), onde se reproduz uma experiência efetuada no MIT que busca simular o funcionamento do mercado, com sua estrutura de distribuição, tempos de produção e transporte e custos que envolvem as operações das "empresas", através de um jogo de empresas. Para comprovar que há redução nos custos, as "empresas" devem remunerar seu capital de giro. Desta forma, estoques geram custos financeiros.

A ação conjunta das empresas é simulada por um programa de computador, onde um algoritmo de programação linear reproduz as regras do jogo. Como resultado, tanto na experiência do MIT como na efetuada pelos autores do artigo, os custos obtidos pelas empresas estiveram muito acima do possível caso houvesse perfeita coordenação das ações dos componentes da cadeia de valor. Além disto, pequenas flutuações na demanda provocam grandes oscilações nos estoques e na produção, dadas as interfaces entre as empresas.

O estudo de modelagem concluiu que a coordenação da cadeia de suprimentos consegue drásticas reduções nos estoques. Estas reduções correspondem a um aumento do giro do estoque e a uma menor necessidade do capital de giro. Também foi útil para exemplificar a importância do fluxo da informação ao longo da cadeia.

Percebe-se que para a implantação do SCM e do ECR ser bem-sucedida é necessária a ruptura das barreiras internas entre as empresas. Neste sentido, é imprescindível a formação de grupos multifuncionais formados por empresas de vários setores, cujos líderes devem ser os gerentes de logística. O objetivo é aumentar a utilidade percebida pelos clientes, através da agregação de serviços, pela presteza do atendimento e/ou pela possibilidade de entrega de produtos customizados com pequeno tempo de delay (FIGUEIREDO \& ZAMBOM, 1998).

Figura 1: Impactos do SCM sobre o Retorno sobre o Investimento (ROI).

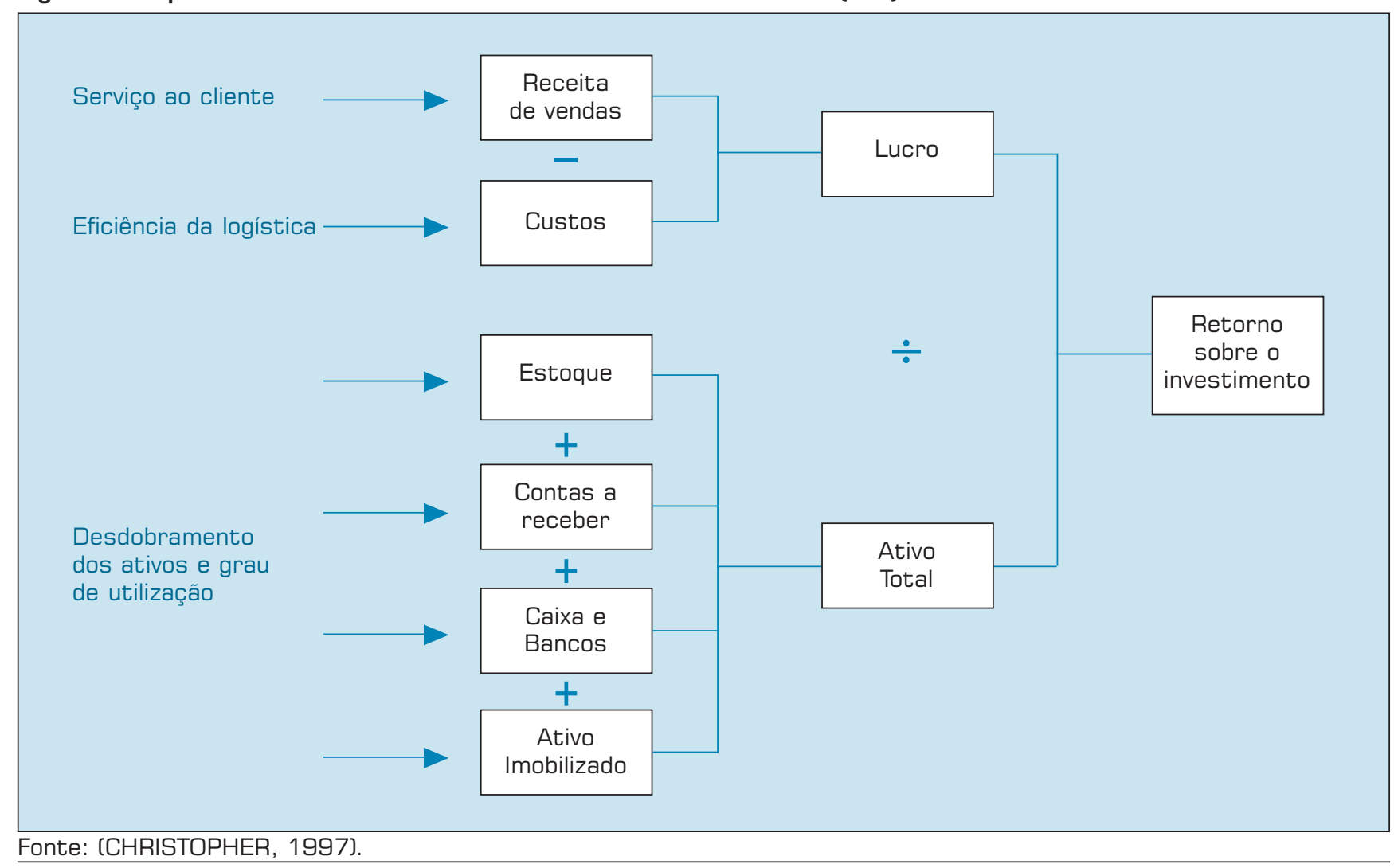


Neste sentido, os gerentes de logística devem centrar suas decisões com base no retorno sobre o investimento (RSI), que é dado pela seguinte relação:

$$
R S I=\frac{\text { lucro }}{\text { ativ. } \text { total }}=\frac{\text { lucro }}{\text { vendas }} \cdot \frac{\text { vendas }}{\text { ativ. } \text { total }}
$$

A primeira parte da fórmula corresponde à margem de lucro e a segunda, ao giro do ativo. Desta forma, o aumento da rentabilidade pode ser conseguido a partir da melhoria em uma ou outra relação, ou até mesmo nas duas simultaneamente. A Figura 1 permite determinar onde o SCM pode trazer melhorias para a rentabilidade.

A disponibilidade de mercadorias é um dos fatores que contribuem para o faturamento. A logística bem gerenciada permite uma disponibilidade adequada (que não haja falta de bens e com isso queda de vendas), fazendo com que o faturamento se mantenha ou até cresça, mantidas as demais condições do mercado. Quanto maior o nível de serviços da empresa, maiores serão os custos. Assim, elevar o serviço tem uma limitação, principalmente se os custos crescerem proporcionalmente mais do que as receitas.

A eficiência da logística permite que os custos do nível de serviço sejam menores do que os da concorrência, garantindo maior lucratividade e/ou crescimento da participação do mercado. Os impactos sobre o lucro a partir do gerenciamento logístico podem ser conseguidos mais facilmente com o SCM. Acordos de ressuprimento automático e de padronização de procedimentos logísticos podem trazer um aumento do serviço, com redução de custos. Contudo, é no ativo total que os efeitos do SCM podem ser vistos com maior intensidade.

A adoção de alianças que permitam a implantação do just-in-time e do quick-response entre as empresas pode trazer grandes reduções nos estoques dos participantes. Em empresas industriais e comerciais a maior parte dos investimentos no ativo encontra-se na forma de estoques (CHRISTOPHER, 1997). Conseguindo reduzir esta rubrica, haverá aumento no RSI, visto que a mesma compõe o denominador da relação. ${ }^{i i i}$

Uma das técnicas utilizadas pelo SCM é a segmentação de mercado, que consiste em identificar, no universo total de clientes, subconjuntos que apresentam comportamentos similares. $\mathrm{O}$ comportamento pode ser quanto à freqüência de compra, tamanho médio da compra, características dos bens e preços dos mesmos. As pesquisas de mercado permitem definir padrões de atendimento para os diversos subconjuntos de clientes.

Clientes com compras constantes permitem a manuten- ção de menores níveis de estoque, uma vez que é possível utilizar técnicas estatísticas para previsão da demanda a curto prazo e adotar sistemas de reposição de estoques como o just-in-time e o quick-response. Por sua vez, clientes com compras esporádicas provocam aumento nos estoques. Desta forma, caso se deseje manter o nível de atendimento $^{i v}$, é necessário adotar a seleção de clientes, através do ajuste do mix das lojas e/ou com campanhas promocionais.

Para os fornecedores dos supermercados, a seleção pode ser feita com tratamento diferenciado às redes que façam parte de parcerias e mantenham compras constantes. Os incentivos podem incluir desde descontos diferenciados até apoio para campanhas promocionais conjuntas.

\section{ara obter a máxima capacidade de crescimento, a cadeia se utilizará de instrumentos de gestão: o lead time}

A seleção de clientes com o intuito de redução de estoque explica-se pela importância desta rubrica na necessidade de capital de giro (NCG). A ampliação dos estoques repercutirá no aumento da NCG do supermercado, entendida como a diferença entre as contas a receber e a pagar mais os estoques (BRASIL, 1993). Para compensar este aumento, podem-se adotar maiores margens. Mas isto só é possível dentro de certos limites e para alguns segmentos, o que com certeza não é o caso dos supermercados. Outras alternativas são reduzir o prazo de recebimento (PR) e/ou ampliar o prazo de pagamento (PP), o que dependerá do poder de barganha da empresa junto aos fornecedores e da concorrência.

$\mathrm{Na}$ tentativa de exemplificar os efeitos que o ECR pode trazer para o NCG das empresas envolvidas, elaborou-se a Figura 2. Nela estão presentes algumas das tensões que podem ocorrer nas negociações entre os componentes da cadeia de suprimentos dos supermercados.

Suponhamos que o supermercado, para reduzir a necessidade de capital de giro, negocie junto aos fornecedores uma ampliação do seu prazo de pagamento (PP) e reduza seu estoque. Isso é contrário às necessidades do atacadista, uma vez que irá provocar um aumento da sua NCG e estoque. Para contrabalançar estes efeitos, ele buscará ampliar o prazo de pagamento junto aos fabricantes e reduzir estoques, o que repercutirá no aumento da NCG dos fabricantes via ampliação do prazo de recebimento e do nível de estoques. De fato, pode ser observado na Figura 2 que o efeito de uma redução de estoques não sincronizada por parte dos supermercados provocará um aumento da NCG da 
cadeia de suprimentos e gerará ineficiência no sistema.

Em outras palavras, se cada componente da cadeia tentar buscar seu ponto de ótimo isoladamente, o ótimo possível para estas empresas não será atingido. O raciocínio é similar aos estudos de modelagem já citados, onde flutuações na demanda final geram grandes movimentos nos processos de compra para o fornecedor primário.

Campos (2000) argumenta que a adoção do ECR no ramo de supermercados tem intensificado a concentração do mesmo, através das fusões e aquisições. Segundo o autor, a redução da necessidade de capital de giro nas grandes redes permite que estas invistam suas sobras de caixa na aquisição das redes menores. Argumenta, ainda, que grande parte das aquisições tem sido feita com capital estrangeiro, mas que isto é reflexo da adoção da mesma técnica nos países de origem das empresas adquirentes.

Portanto, o ECR é uma ferramenta de gestão que tem permitido o crescimento das firmas participantes. Contudo, sabe-se que o crescimento da firma acima do seu potencial de financiamento pode gerar profundos problemas financeiros e aumentar o risco de falência, pois quando a NCG cresce mais que a capacidade de financiamento própria, o endividamento cresce. Ademais, caso as taxas de juros do mercado financeiro sejam maiores do que a rentabilidade do ativo econômico da firma, o desequilíbrio financeiro da empresa surge com grande rapidez, podendo comprometer sua permanência no mercado (BRASIL \& BRASIL, 1993).

É notório que a economia brasileira apresenta juros reais dos mais altos do mundo. Nestas condições, crescimento com endividamento financeiro não é recomendável, pois inclusive as empresas que captam recursos no mercado externo têm que pagar taxas de risco mais elevadas e ainda arcam com o risco de mudanças nas taxas de câmbio, como as ocorridas em 1999.

Diante deste contexto, busca-se, neste artigo, construir um modelo teórico que permita o crescimento equilibrado das firmas. Ou seja, pretende-se maximizar a diferença entre a capacidade de financiamento da firma e sua NCG, a partir de um modelo de otimização dinâmica.

O modelo foi elaborado para uma cadeia de suprimentos, partindo-se do princípio de que a ação isolada dos supermercados para reduzir sua NGC gerará ineficiência e que a solução ótima será obtida a partir da otimização da gestão financeira ${ }^{v}$ da cadeia como um todo.

A seção seguinte traz a modelagem para uma aplicação do ECR no mercado de hiper e supermercados com base em um modelo de programação dinâmica.

\section{O MODELO}

Partiu-se da identidade contábil, que reflete a necessidade de capital de giro:

Figura 2: Efeito de uma redução de estoques não sincronizada sobre a NCG de uma cadeia de suprimentos.

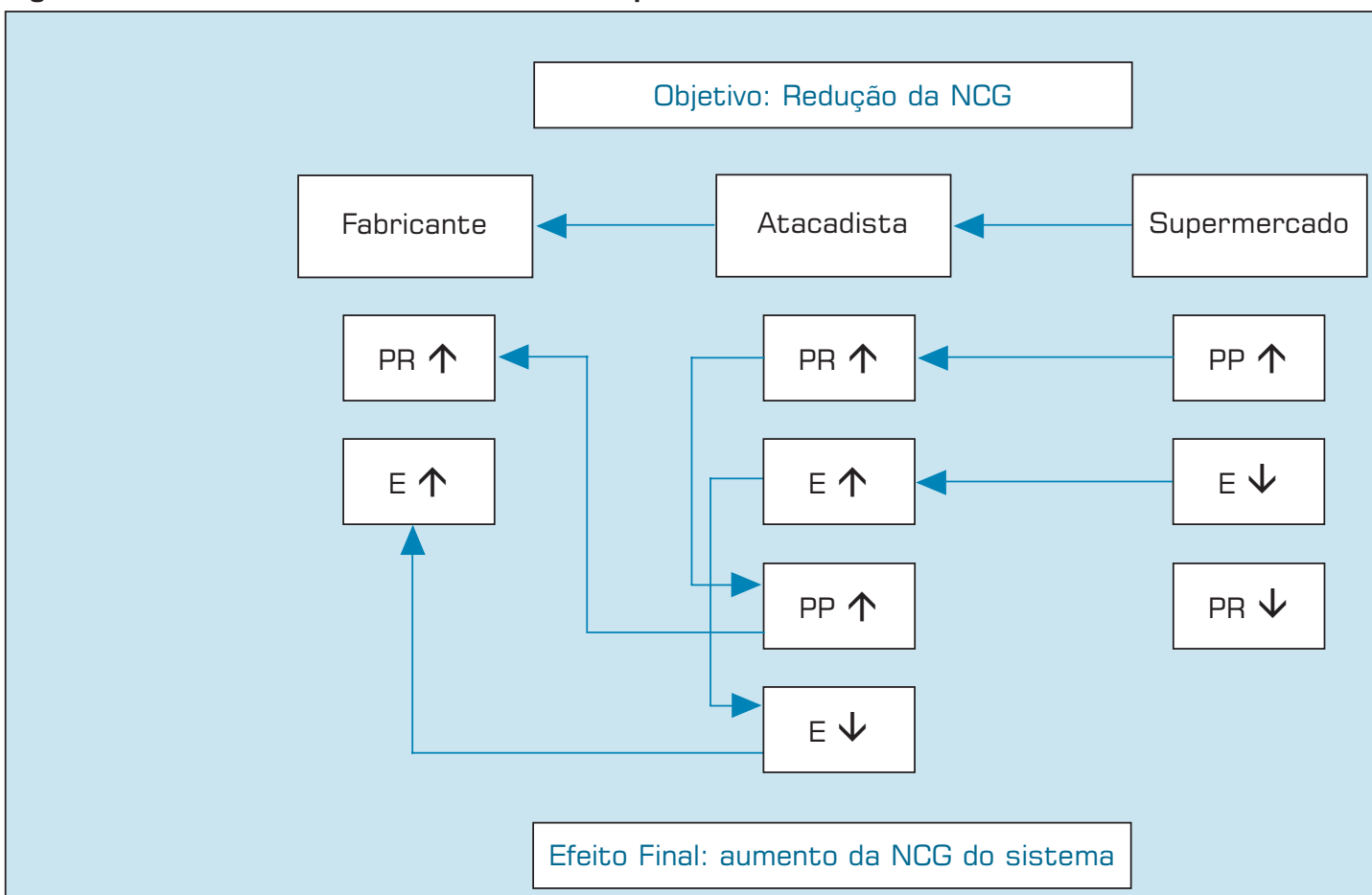


$N C G=R+E-P$

em que:

$N C G=$ Necessidade de Capital de Giro;

$R=$ contas a receber;

$E=$ estoques; e

$P=$ contas a pagar.

Para uma cadeia de suprimentos, tem-se que: ${ }^{i} N C G\left({ }^{i} R,{ }^{i} E,{ }^{i} P\right)$, em que o índice $i$ indica qual a posição da empresa na cadeia produtiva. Por simplicidade, supôs-se uma cadeia de suprimentos com 3 diferentes agentes: fabricantes $(i=1)$; atacadistas $(i=2)$; e supermercados $(i=3)$.

Quando os componentes da cadeia unem-se para adotar ações conjuntas visando o crescimento equilibrado da firma, constata-se que a necessidade de capital de giro de um componente está intimamente relacionada à necessidade de capital de giro do outro. Matematicamente, temse: ${ }^{1} R={ }^{2} P e{ }^{2} R={ }^{3} P$.

Nesta formulação não se supõe que o fornecedor venda apenas para uma empresa, nem que a empresa compradora supre-se de apenas um fornecedor, mas que as empresas consideram as demais transações como exógenas para as decisões a serem tomadas na parceria.

Similarmente, os estoques dos parceiros estão relacionados. Conforme descrito na seção anterior, a parceria permite que todos os membros da cadeia reduzam seus estoques, a partir do conhecimento da demanda final. A igualdade matemática apresentada pelo item contas a receber não existe, pois envolve complicadores da produção e entrega que não permitem que todos os membros da aliança tenham o mesmo estoque.

Partindo-se deste raciocínio, a necessidade de capital de giro da cadeia de suprimentos está relacionada com dois principais parâmetros externos: o prazo de pagamento que o fornecedor da cadeia tem com seus fornecedores de matériasprimas, que não participam da aliança; e o comportamento das vendas finais que o supermercado realiza.

Desta forma, as decisões da cadeia devem ser tomadas em conjunto, observando-se a seguinte função: $N C G\left({ }^{3} R,{ }^{3} E,{ }^{1} P\right)$. Ou seja, devem-se tomar medidas administrativas levando-se em conta as peculiaridades do varejista que atende ao consumidor final e as limitações de crédito que o componente da cadeia mais afastado da demanda final encontra. Mais precisamente: $N C G={ }^{3} R+{ }^{3} E,+{ }^{1} P$, ou seja, utiliza-se neste paper a relação contábil proposta por Brasil \& Brasil (1993).

$\mathrm{Na}$ realidade, as empresas que participam da cadeia e utilizam as técnicas do ECR buscam uma ampliação de sua capacidade de fazer investimentos de longo prazo, sem que haja um comprometimento do giro operacional. Ou seja, o objetivo das empresas é maximizar a capacidade de crescimento (CC), entendida como a diferença entre capacidade de financiamento e necessidade de capital de giro, de sorte que:

$C C=C F-N C G$

$C F$ corresponde à capacidade de financiamento próprio, ou endógeno, pois não se considera aqui o endividamento financeiro.

Entende-se que apenas uma parte dos lucros da empresa será destinada à ampliação da capacidade produtiva. Para facilitar a análise, o modelo foi simplificado e será considerado apenas o relacionamento dos lucros com o custo para diminuir os lead times das entregas. Desta forma,

$C F(L(\omega, \varphi))=a \cdot[\omega-c(\varphi)]$

em que:

$L=$ lucro

$\omega=$ vendas

$\varphi=$ lead time

$a=$ constante entre $(0,1]$ que representa o percentual

do excedente utilizado na $\mathrm{CF}$.

A função custo do lead time $(c(\varphi))$ satisfaz as condições normais de uma função custo, ou seja, ela é positivamente inclinada e côncava.

Como as decisões num determinado instante de tempo têm influência nas decisões futuras da cadeia, e supondo que nenhuma das empresas que compõem a parceria tenha intenção de quebrar o acordo, de forma que não há um tempo predeterminado para o fim das tomadas de decisão conjunta, tudo se passa como se o horizonte de decisão fosse infinito e o objetivo da cadeia é maximizar a capacidade de crescimento ao longo do tempo. A função objetivo da cadeia de suprimentos é então pelo funcional:

$\operatorname{Max}_{\varphi, \theta} \int_{0}^{\infty}\left\{C F[L(\omega(\theta), \varphi)]-N C G\left[{ }^{3} R,{ }^{3} E,{ }^{1} P\right]\right\} d t$

em que:

$\theta=$ prazo médio de vendas a prazo;

Para obter a máxima capacidade de crescimento, a cadeia se utilizará de dois instrumentos de gestão: o lead time (tempo de demora para o recebimento do pedido, $\varphi$ ) e o prazo de pagamento $(\theta)$. Estas são, então, as variáveis de controle do modelo. O foco de estudo, portanto, são as medidas típicas de procedimentos logísticos do ECR.

Substituindo (1) e (2) em (3) e simplificando a notação, tem-se:

$$
\operatorname{Max} \int_{0}^{\infty}\{a[\omega-c(\varphi)]+P-R-E\} d t
$$

Entretanto, a maximização não é incondicional e deve respeitar as dinâmicas das vendas $(\omega)$, das contas a receber $(R)$ e do estoque $(E)$. Estas variáveis são as que estabelecem 
o estado da parceria e assim são as variáveis de estado do modelo. As dinâmicas são representadas pelo seguinte sistema de equações diferenciais:

$\left\{\begin{array}{l}\dot{\omega}=\omega f(\theta) \\ \dot{R}=-g(\theta)+h(\theta) f(\theta) \omega ; \\ \dot{\mathrm{E}}=\omega \varphi b \operatorname{sen} \frac{u t}{\varphi \omega}\end{array}\right.$
com as seguintes condições iniciais:
$\omega(0)=\omega_{0}, R(0)=0, E(0)=E_{0}$
em que:
$\dot{\omega}, \dot{R}$ e E são as variações no tempo de cada uma
das variáveis;
b e u $=$ são parâmetros de ajuste de unidade e de
proporcionalidade;
$\mathrm{t}=$ tempo;
$f(\theta)$ é uma função que pondera as variações nas
vendas devido a variações no prazo de pagamento;
$g(\theta)$ são os recebimentos;
$h(\theta)=$ percentual da variação de vendas a prazo.

A equação (5) indica que as vendas têm, dado um determinado prazo de pagamento, uma taxa de crescimento constante no tempo, ou seja, em termos econômicos a demanda é crescente. A velocidade de crescimento das vendas mudará caso o prazo de pagamento se altere. Isto é, as vendas variam dependendo da política de vendas a prazo da empresa.

Supõe-se que a função que relaciona a variação das vendas e o prazo de pagamento, $f(\theta)$, é crescente e côncava (por exemplo, $f(\theta)=$ m. $\theta^{n}$, com $\mathrm{n}<1$ ). Ou seja,

$\frac{d f}{d \theta}<0 ; \quad \frac{d^{2} f}{d \theta^{2}}<0$

economicamente o aumento do prazo de pagamento faz crescer as vendas, mas a taxas decrescentes. Adicionalmente, supõe-se que deve haver valores de $\theta$ altos e baixos o suficiente que não atraia novos consumidores.

A equação (6) representa a dinâmica do item contas a receber. Para deduzi-la partiu-se da definição básica de contas a receber e fizeram-se simulações para diferentes planos de pagamento, observando-se os valores de estabilidade das contas a receber (quando as vendas são constantes) e levando em consideração que os prazos poderiam mudar a cada novo período. A equação foi então generalizada e deu origem a uma equação a diferenças finitas. Tomou-se então o limite transformando a dinâmica discreta em uma dinâmica contínua representada por uma equação diferencial, que foi a base da formulação da equação (6). Com a adoção deste procedimento, incluíram-se prazos de pagamento dentro do conjunto dos números reais, ou seja, o modelo suporta prazos de pagamentos que podem ser inclusive instantâneos.

A equação de movimento do estoque (7) é um ajustamento suave da demanda no formato "dente de serra", sem as limitações impostas pelos pressupostos usuais de recebimento de mercadorias em um único momento e vendas lineares. ${ }^{v i} \mathrm{O}$ parâmetro $u$ tem a dimensão rad/ s, ou seja, é uma velocidade típica para cada parceria, podendo ser interpretado neste modelo como a velocidade com que as vendas ocorrem nos check-outs dos supermercados. Apesar de sua complexidade, permite que o modelo se torne mais próximo aos reais movimentos médios dos estoques ao longo do tempo nos supermercados, pois, como os pedidos não chegam todos no mesmo momento, é natural que o estoque flutue respeitando certos parâmetros.

Percebe-se através da equação (7) que a amplitude de flutuação do estoque depende das vendas e do lead time. De fato, quanto maiores as vendas, maiores terão que ser os pedidos de reposição, para se manter o mesmo nível de estoque. Os estoques então serão menores se, dada uma quantidade de venda constante, houver uma diminuição no lead time ou, para um dado lead time, houver uma diminuição nas vendas. É interessante ressaltar que as decisões são tomadas a cada instante e que as vendas são contínuas, de forma que uma diminuição nas vendas é suave e não acarretará em aumento de estoque, o que seria esperado se as vendas caíssem abruptamente.

Com relação ao tempo de demora no recebimento de mercadorias, pode-se notar pela equação que quanto maior for este tempo, maiores terão que ser as compras. Ao mesmo tempo, a frequiência também será influenciada pelas vendas e pelo lead time. Neste caso, contudo, a relação é inversa, ou seja, quanto menores as vendas e o tempo de espera, maior será a freqüência.

\section{SUPOSICÕES E LIMITACÕES}

A modelagem exigiu algumas suposições e limitações sobre o comportamento das variáveis. Algumas desta limitações já foram tratadas na seção anterior. Esta seção traz a síntese de outras suposições do modelo, que ainda não foram devidamente comentadas:

- os preços são estáveis a ponto de não haver cobrança de juros nas compras a prazo. Isso pode ser devido a esta estabilidade ou por uma imposição legislativa, quando os preços a prazo e à vista têm que ser os mesmos por lei e o consumidor escolhe apenas se vai ou não financiar os juros embutidos neles. Apesar desta hipótese parecer 
um pouco forte, confrontada com a afirmação de que as taxas de juros do mercado financeiro brasileiro estão entre as mais elevadas do mundo, na prática percebe-se que no setor de supermercados os prazos envolvidos nas compras não são elevados e a competitividade do setor impossibilita a cobrança deste tipo de encargo de forma aberta, a mídia falada e escrita dispõe de exemplos diários a este respeito;

- a taxa de crescimento das vendas é constante. Como estão sendo trabalhados valores agregados de diversos produtos de grandes redes, é razoável supor que a demanda que as empresas estarão atendendo cresça constantemente, ou seja, em crescimento exponencial, por conta do crescimento populacional, esta é uma suposição plausível pelo menos em países em desenvolvimento (SOLOW, 1974). Note-se que pelo modelo proposto, no caso de a empresa praticar prazos muito diferentes do mercado, não irá atrair novos consumidores (a variação das vendas será nula), e o supermercado estará relativamente perdendo mercado;

- a dedução da equação da variação das contas a receber tem como pressuposto poder haver prazos de pagamento infinitesimais, o que retira o caráter discreto inicial da equação. Entende-se que como uma parcela das vendas é efetuada à vista e outra a prazo, o prazo médio pode assumir qualquer valor em reais;

- os prazos de pagamento oferecidos pelos supermercados aos clientes podem ser controlados. A princípio esta afirmação pode parecer forte, mas nota-se que na prática o supermercado exerce algum tipo de controle sobre o prazo de pagamento das vendas. Alguns exemplos são: i) promoções com datas de pagamento fixadas para compras com cheques pré-datados; ii) existência de cartões de crédito do próprio supermercado com prazos de pagamento máximos, que podem ser flexibilizados para alongar o prazo concedido ao cliente;

O modelo é determinístico, com todas as limitações que tal hipótese acarreta.

\section{RESULTADOS}

Com base no modelo proposto, obtém-se a seguinte função Hamiltoniana não autônoma:

As deduções das fórmulas de (8) a (18), para obtenção

\section{Custo Marginal do Lead Time}

$$
c^{\prime}(\varphi)=\frac{b t}{a}\left[\omega \operatorname{sen}\left(\frac{u}{\varphi \omega}\right) t-\frac{u}{\varphi} \cos \left(\frac{u}{\varphi \omega}\right) t\right]
$$

O custo marginal do lead time, $c^{\prime}(\varphi)$, é diretamente proporcional ao parâmetro $b$, que pode ser visto como a frequiência dos pedidos que caracterizam um mercado ou uma demanda particular, e é inversamente proporcional ao percentual do lucro usado como capacidade de financiamento, $a$. Assim, quanto maior o percentual do lucro alocado para a capacidade de crescimento, menor será o custo marginal do lead time, o que, de certa forma, é intuitivo. $\mathrm{O}$ modelo apenas corrobora esta intuição.

Para valores da razão $\frac{u}{\varphi \omega}$ no intervalo

$$
2 k \pi<\frac{u}{\varphi \omega}<(4 k+1) \frac{\pi}{2}, k=(0,1, \ldots \infty),
$$

um aumento nas vendas ou uma redução do lead time implicarão em um aumento dos custos associados. Ou seja, para estes valores um aumento no lead time seria a melhor estratégia, pois reduziria os custos. Desta forma, nem sempre é ótimo para a cadeia ter o menor lead time para obter a maior capacidade de crescimento possível. Isto deve servir de alerta nas tomadas de decisão nestas parcerias, isto é, existem determinados momentos em que a melhor estratégia é aumentar o lead time e não diminuí-lo.

Tal tipo de observação não é comum na bibliografia que trata de técnicas como o SCM e o ECR. Normalmente, enfatizam-se as vantagens pela redução dos prazos, sob os pontos de vista financeiro e mercadológico. Porém, através do modelo observa-se que a redução a qualquer custo pode levar as empresas parceiras a adotarem práticas antieconômicas.

Para valores entre $(4 k+1) \frac{\pi}{2}<\frac{u}{\varphi \omega}<\pi(1+2 k)$

os custos aumentam com as vendas e o lead time. Aqui a cooperação, utilizando-se do conceito ECR, seria a melhor solução.

$$
\text { Já no intervalo } \pi(1+2 k)<\frac{u}{\varphi \omega}<(8 k+5) \frac{\pi}{4}
$$

um aumento nas vendas ou uma redução do lead time implicarão em diminuição dos custos $c^{\prime}(\varphi)$. Existem instantes onde as ações conjuntas são vantajosas, no sentido proposto pelo ECR e é nestes intervalos que se podem aplicar as técnicas propostas pelo ECR.

$$
H=\left\{a[\omega-c(\varphi)]+P-R-E+\lambda_{1} \omega f(\theta)+\lambda_{2}[h(\theta) f(\theta)-g(\theta)]+\lambda_{3} \omega \varphi b \operatorname{sen} \frac{u}{\varphi \omega} t\right\}
$$

dos resultados intermediários, podem ser acompanhadas no Apêndice.

Os resultados abaixo representam as condições para se obter a máxima capacidade de crescimento para a cadeia.
Observam-se também pontos que poderiam representar os regimes de implantação da técnica, ou seja, pontos onde as combinações de valores de lead time e vendas no intervalo

$$
(8 k+3) \frac{\pi}{4}<\frac{u}{\varphi \omega}<2 \pi(k+1)
$$


acarretariam custos marginais negativos. Pode ser que seja nestes intervalos que a implementação da técnica traga seus maiores benefícios.

Como para certos intervalos a redução do lead time aumentaria o custo, é importante para a cadeia de suprimentos utilizar marketing conjunto para que não ocorram efeitos negativos sobre os lucros com a adoção do ECR. Esta conclusão corrobora os resultados encontrados por Christopher (1997) e Santos et al. (1998).

Percebe-se, então, que a prática de reposição contínua, apesar de desejável para conquistar melhores posições competitivas, pode não ser viável para todos os instantes de decisão da parceria. Este alerta quase sempre é esquecido na bibliografia consultada que versa sobre o tema. Uma das explicações para que a prática de um lead time constante (ou contínuo) tenha sido aceita sem restrições é que o valor deste, dada a capacidade tecnológica, ou mesmo física, implique num ponto de operação viável ao crescimento da $\mathrm{CC}$, porém, não necessariamente o ponto de crescimento ótimo desta.

O uso de estratégias dinâmicas poderá acelerar a CC de uma Cadeia Produtiva.

Estes resultados são importantes, pois indicam que, dadas as condições da demanda, pode ser vantajoso ou não reduzir o lead time, podendo ser o ponto de partida para estudos que objetivem determinar empiricamente qual o lead time ideal e a viabilidade de uma possível parceria. Além disso, generaliza o ECR como um conjunto de ações, ou seja, uma estratégia, não trivial. O lead time deve obedecer uma dinâmica própria para otimização, às vezes aumentando, às vezes diminuindo. Assim, a gestão do lead time depende das características das empresas envolvidas na parceria e a administração deste não é estática como sempre foi proposto.

\section{Custo de Oportunidade das Vendas}

A equação (16) representa a variável de co-estado associada à equação de movimento das vendas. Assim, ela representa o custo de oportunidade das vendas ou o valor que a cadeia estaria disposta a ceder para obter um acréscimo igual na capacidade de crescimento.

$$
\lambda_{1}=\left[\frac{\lambda_{2}}{f^{\prime}(\theta)}\right]\left[\frac{g^{\prime}(\theta)}{\omega}-h^{\prime}(\theta) f(\theta)-h(\theta) f^{\prime}(\theta)\right](16)
$$

Pode ser observado na equação que o custo de oportunidade da receita, $\lambda_{1}$, independe do lead time, é diretamente proporcional ao valor implícito das contas a receber, $\lambda_{2}$, e é inversamente proporcional às vendas, $\omega$. Esta equação apenas fortalece os resultados teóricos, pois são resultados esperados, ou seja, é de se esperar que a capacidade de crescimento fique mais restrita com a diminuição das vendas e o aumento das vendas a prazo.
Além disso, a variação do lead time não restringirá mais ou menos a CC.

A equação anterior também pode ser escrita na seguinte forma:

$$
\lambda_{1}=\left[\frac{\lambda_{2}}{\omega f^{\prime}(\theta)}\right]\left\{\frac{-d}{d \theta}[-g(\theta)+\omega h(\theta) f(\theta)]\right\}
$$

Nesta forma as afirmações do parágrafo anterior ficam mais explícitas. Note que o termo entre chaves é o impacto de uma variação no prazo de pagamento na variação das contas a receber (equação (6)).

\section{Valores Implícitos das Contas}

\section{a Receber e da Acumulação de Estoque}

Finalmente, através do modelo observou-se que o valor implícito das contas a receber e da acumulação de estoque, para se ter uma capacidade de crescimento ótima, deve crescer linearmente com o tempo (equações (12) e (14), respectivamente).

$$
\begin{aligned}
& \lambda_{2}=t+k_{2} \\
& \lambda_{3}=t
\end{aligned}
$$

Na equação (12) tem-se explicitado o valor implícito das contas a receber. A variável $k_{2}$ é uma constante de integração e, portanto, assumirá valores específicos conforme o caso, não tendo um significado econômico específico. $\mathrm{O}$ valor implícito cresce linearmente com o tempo, principalmente em função da suposição de crescimento exponencial das vendas, que faz com que as contas a receber cresçam com o passar do tempo.

Com a técnica de ECR espera-se que os estoques diminuam, o que aumentará sua escassez e seu valor implícito de acumulação.

\section{CONSIDERAC̣̃̃ES FINAIS}

Este artigo utilizou a maximização da capacidade de crescimento como o objetivo que as empresas do setor de supermercados que participam de alianças estratégicas do tipo ECR devem ter. Ou seja, essas empresas desejam diminuir ao máximo a necessidade de capital de giro, sem que a participação no mercado se reduza. O modelo dinâmico proposto considera como estratégias administrativas conjuntas o prazo de pagamento e o lead time.

Concluiu-se que, dadas as condições da demanda, pode ser ótimo reduzir ou não o lead time, uma vez que o custo marginal do lead time variou ora diretamente, ora inversamente com esta variável, o que demonstra que a prática de reposição contínua, apesar de desejável para conquistar 
melhores posições competitivas, pode não ser viável em todos os instantes das tomadas de decisão conjuntas. A política ótima do lead time com relação ao custo é totalmente desvinculada da política de prazo de pagamento.
Uma vez que as funções e os parâmetros forem obtidos, os cálculos das políticas ótimas se explicitarão e os caminhos ótimos a serem seguidos, neste caso particular, serão determinados.

As demais conclusões encontradas não são específicas, uma vez que o problema foi tratado do ponto de vista teórico e nem todas as formas funcionais foram definidas. Através de simulação ou estudos de caso para cálculo dos valores dos parâmetros poder-se-ão

\section{A política ótima do lead time com relação - ao custo é totalmente desvinculada} da política de prazo de pagamento obter resultados menos abstratos. O levantamento das formas funcionais pode ser obtido através de dados experimentais. É o caso das funções $\mathrm{h}, \mathrm{f}$ e g. A g depende mais explicitamente do comportamento do consumidor perante políticas governamentais, ela capta, além de outras coisas, a inadimplência. O parâmetro "a" é uma decisão da cadeia e se fosse utilizado como variável de controle a solução seria óbvia e sem implicações práticas, desta forma, este parâmetro poderá ser definido diretamente sem experimentos.

Os parâmetros "b" e "u" são deduzidos quando do levantamento dos dados, pois são apenas ajustes de unidades.

Aqui as conclusões são independentes de um caso particular, de formas funcionais, de valores de parâmetros e obviamente de dados.

O modelo preliminar proposto é o início de estudos sobre as políticas administrativas que as empresas podem adotar em alianças estratégicas. O modelo contém algumas limitações que deverão ser abordadas em futuros estudos. A principal delas diz respeito ao caráter da demanda. Um modelo mais realístico deveria tratar a demanda como algo aleatório. Esta mudança traria, possivelmente, outros resultados relevantes.

$$
\begin{aligned}
& \text { APÊNDICE } \\
& H=\left\{a[\varpi-c(\varphi)]+P-R-E+\lambda_{1} \omega f(\theta)+\lambda_{2}[h(\theta) f(\theta) \omega-g(\theta)]+\lambda_{3} \omega \varphi b \operatorname{sen} \frac{u}{\varphi \omega} t\right\} \\
& \frac{\partial H}{\partial \varphi}=-a c^{\prime}(\varphi)+\lambda_{3} \omega b \operatorname{sen} \frac{u}{\varphi \omega} t-\lambda_{3} \frac{b u}{\varphi} \cos \frac{u}{\varphi \omega} t=0 \\
& \frac{b}{a} \lambda_{3}\left[\omega \operatorname{sen}\left(\frac{u}{\varphi \omega}\right) t-\frac{u}{\varphi} \cos \left(\frac{u}{\varphi \omega}\right) t\right]=c^{\prime}(\varphi) \\
& \frac{\partial H}{\partial \theta}=\lambda_{1} \omega f^{\prime}(\theta)+\lambda_{2}\left[h^{\prime}(\theta) f^{\prime}(\theta) \omega+h(\theta) f^{\prime}(\theta) \omega-g^{\prime}(\theta)\right]=0 \\
& \lambda_{1} f^{\prime}(\theta)=\lambda_{2}\left[\frac{g^{\prime}(\theta)}{\omega}-h^{\prime}(\theta) f^{\prime}(\theta)-h(\theta) f^{\prime}(\theta)\right]
\end{aligned}
$$




$$
\begin{aligned}
& \dot{\lambda}_{1}=-\frac{\partial H}{\partial \omega}=-\left[a+\lambda_{1} f+\lambda_{1} h f+\lambda_{3} \varphi b \operatorname{sen}\left(\frac{d}{\varphi \omega}\right) t-\lambda_{3}\left(\frac{d b}{\omega}\right) \cos \left(\frac{d}{\varphi \omega}\right) t\right] \\
& \dot{\lambda}_{1}=\lambda_{3} b\left[\left(\frac{d}{\omega}\right) \cos \left(\frac{d}{\varphi \omega}\right) t-\varphi \operatorname{sen}\left(\frac{d}{\varphi \omega}\right) t\right] \lambda-\left[a+\lambda_{1} f(\theta)+\lambda_{2} h(\theta) f(\theta)\right] \\
& \dot{\lambda}_{1}+\lambda_{1} f(\theta)=\lambda_{3} b\left[\left(\frac{d}{\omega}\right) \cos \left(\frac{d}{\varphi \omega}\right) t-\varphi \operatorname{sen}\left(\frac{d}{\varphi \omega}\right) t\right] \lambda-\left[a+\lambda_{2} h(\theta) f(\theta)\right] \\
& \dot{\lambda}_{2}=-\frac{\partial H}{\partial R}=-(-1) ; \\
& \dot{\lambda}_{2}=1 \\
& \lambda_{2}=t+k_{2} \\
& \dot{\lambda}_{3}=-\frac{\partial H}{\partial E}=-(-1) ; \quad \dot{\lambda}_{3}=1 \\
& \lambda_{3}+k_{3}
\end{aligned}
$$

Como se pode escolher $E_{0}$ de tal forma que $\lambda_{3}(0)=0$, então,

$$
\lambda_{3}=t
$$

Substituindo (9) e (12) em (11), tem-se:

$$
\dot{\lambda}_{1}+\lambda_{1} f(\theta)=-\left[c^{\prime}(\varphi) a\left(\frac{\varphi}{\omega}\right)+a+\left(t+k_{2}\right)(h(\theta) f(\theta))\right]
$$

Substituindo (12) em (10) e explicitando $\lambda_{1}$, tem-se:

$$
\lambda_{1}=\left[\frac{t+k_{2}}{f^{\prime}(\theta)}\right]\left[\frac{g^{\prime}(\theta)}{\omega}-h^{\prime}(\theta) f(\theta)-h(\theta) f^{\prime}(\theta)\right]
$$

Em que $\lambda_{1}$ é o custo de oportunidade da receita. 
De (9) e sabendo que c' $(\varphi)>0$, obtém-se:

$\omega \operatorname{sen}\left(\frac{u}{\varphi \omega}\right) t>\frac{u}{\varphi} \cos \left(\frac{u}{\varphi \omega}\right) t$

Seja $\gamma=\left(\frac{u}{\varphi \omega}\right)$, então, $\quad \operatorname{sen} \gamma t>\gamma \cos \gamma t \quad$ ou $\quad \operatorname{sen} \gamma t-\gamma \cos \gamma t>0$. Elevando ao quadrado, tem-se:

$\operatorname{sen}^{2} \gamma t-2 \gamma \operatorname{sen} \gamma t \cos \gamma t+\cos ^{2} \gamma t>0$. Assim, $2 \gamma \operatorname{sen} \gamma t \cos \gamma t<1 . \log 0$

$\gamma \operatorname{sen} 2 \gamma t<1$

Substituindo (14) em (9):

$$
c^{\prime}(\varphi)=\frac{b t}{a}\left[\omega \operatorname{sen}\left(\frac{u}{\varphi \omega}\right) t-\frac{u}{\varphi} \cos \left(\frac{u}{\varphi \omega}\right) t\right]
$$

\section{- Notas}

$i$ "The main constraint to emitting a supply chain with market sales data is the common attitude that information is power". (p. 68)

ii Para uma melhor discussão sobre cada uma dessas técnicas consultar: Campos (2000); Christopher (1997). iii O SCM pode trazer a redução de investimentos em caixa e contas a receber, pois, automatizando processos de faturamento, o pedido demorará menos tempo para transformar-se em fatura e, portanto, passar a contar o prazo de recebimento. Contudo, esta redução será considerada, para efeito deste artigo, desprezível. iv Como nível de atendimento entendese a concepção de logística, que é o percentual de pedidos atendidos totalmente em uma determinada fração de tempo. Por exemplo, um nível de serviço de $95 \%$ em 24 horas significa atender $95 \%$ dos pedidos no primeiro dia. Quanto maior o nível de serviço, maior a necessidade de se manter estoques.
${ }^{v}$ Entende-se neste ponto a otimização da gestão financeira como manter um crescimento equilibrado.

vi Para modelos que descrevem este tipo de comportamento, ver, por exemplo, Corrêa (1987) e Ching (1999).
BRASIL, Haroldo Vinagre. Gestão financeira das empresas: um modelo dinâmico. 2. ed. Rio de Janeiro Qualitymark, 1993.

CAETANO, José Roberto. Jogo rápido: como o francês Casino vai mudar o jeito do Pão de Açúcar fazer negócios. EXAME, São Paulo, p. 49-50, ago./1999.

CAMPOS, Luís Henrique R. O Supply Chain Management e seus reflexos na concorrência. 2000. Dissertação (mestrado em economia) - Depto. de Economia, UFPB, João Pessoa.

CHING, Hong Yuh. Gestão de estoques na cadeia de logística integrada: supply chain. São Paulo: Atlas, 1999.
CHRISTOPHER, Martin. Logística e gerenciamento da cadeia de suprimentos: estratégias para a redução e melhoria dos serviços. São Paulo: Pioneira, 1997.

CORRÊA, Joary. Gerência econômica de estoques e compras. 7. Ed. Rio de Janeiro: FGV, 1987.

FIGUEIREDO, Djairo Guedes de \& NEVES, Aloisio Freira. Equações diferenciais aplicadas. Rio de Janeiro: IMPA, 1997

FIGUEIREDO, Reginaldo Santana; ZAMBOM, Antônio Carlos. A empresa vista como um elo da cadeia de produção e distribuição. REVISTA DE ADMINISTRACÃ̃O, São Paulo, v. 33, n. 3 , p. 29-39, jul./set. 1998.
GARCIA, Maria de Fátima; CAMPOS, Luís Henrique Romani de. O Supply Chain Management é um reflexo de um novo padrão de organização industrial ou apenas um novo método de redução do ciclo do capital. REVISTA DE ECONOMIA DO NORDESTE, Fortaleza, número especial, 1999.

MASON-JONES, Rachel; TOWILL, Denis R. Total cycle compression and the agile supply chain. International Journal of Production Economics, Cardiff, v. 62, p. $61-73,1999$.

MATTOS, Adriana; RODRIGUES, Carlos. Pequenas redes de supermercados contra-atacam. GAZETA MERCANTIL, São Paulo, 17 dez. 1999. caderno c, p. 1-2.
SANTOS, Angela Maria Medeiros M.; GIMENEZ, Luiz Carlos Perez. Reestruturação do comércio varejista e de supermercados. BNDES SETORIAL, Rio de Janeiro, n. 9, p. 79-94, mar. 1999.

SANTOS, Angela Maria Medeiros M.; GIMENEZ, Luiz Carlos Perez; MATTOS, Carolina Barbosa. Hiper e Supermercados no Brasil. Disponíve em http://www.bndes.com.br Acesso em dezembro/1998.

SOLOW, R.M. Intergenerational Equity and Exhaustible Resources. Review of Economic Studies, Symposium. p. 29-45, 1974.

WOOD, ThomazJr:; ZUFFO, Paulo Knörich. Supply Chain Management. Revista de Administração de Empresas. São Paulo, v. 38, n. 3, p. 55-63, jul./set. 1998 